\title{
COSTA RICA: LA DERROTA PREMATURA DE UN GOBIERNO DIVIDIDO
}

\author{
Costa Rica: Early Defeat of a Divided Government
}

\section{STEFFAN GÓMEZ-CAMPOS}

Programa Estado de la Nación de Costa Rica

\section{EVELYN VILLARREAL*}

Programa Estado de la Nación de Costa Rica

\begin{abstract}
RESUMEN
La revisión de hechos ocurridos en 2012 presenta a un gobierno que en su segundo año sufrió importantes derrotas políticas en áreas clave que había señalado para su gestión. La reforma fiscal y la mejora a la infraestructura, como ejes más visibles de la acción gubernamental, tuvieron importantes reveses.

Se mantuvo una gran inestabilidad a lo interno del Ejecutivo, al igual que en 2011; ahora los roces y tensiones también se dieron entre poderes del Estado. Ello unido a cotidianas denuncias por corrupción, crecientes movilizaciones ciudadanas y una alta percepción de insatisfacción con el gobierno, se combinan para caracterizar a este año como uno en donde el gobierno perdió prematuramente su capacidad de conducir la política. Al punto que la Presidenta de la República la considera una nación ingobernable y comisionó a un grupo de notables para rediseñar el sistema político, el cual se suma a los ejercicios de este tipo que han realizado también las administraciones pasadas. Los ciudadanos lo resienten y el índice de apoyo a la democracia presentó en 2012 su nivel más bajo (56\%) desde que existe esta medición en 1978.
\end{abstract}

Palabras clave: Costa Rica, democracia, partidos políticos, elecciones, confianza ciudadana, poderes de la república, movilización social.

\begin{abstract}
A review of events in 2012 finds a government which in its second year in office suffered major defeats across key policy areas. Government commitments on tax reform, security policy, improvement of infrastructure, as well as managing the conflict with Nicaragua, all experienced major reversals or setbacks. Internal feuding continued to beset the Executive. However, in contrast to 2011, internal tensions now spilled over into other branches of the state. The political impasse coupled with daily reports of corruption, growing citizen protest and high levels of popular dissatisfaction with the government served to effectively halt official efforts to advance a legislative programme. In response, the President of the Republic declared the nation ungovernable and commissioned a group of experts to advise on systematic reform -the latest in a series of such exercises undertaken by government in recent years. This panorama has only stoked citizen discontent. The 2012 survey on democratic support in Costa Rica registered its lowest levels of popular support (56\%) since records began in 1978.
\end{abstract}

Key words: Costa Rica, Democracy, Political Parties, Elections, Citizen Confidence, Branches of Government, Social Mobilization.

* Se agradece a Juan Guillermo Murillo, del Programa Estado de la Nación, por su colaboración en la actualización y sistematización de información para este artículo. 


\section{TEMAS SALIENTES EN LA REALIDAD NACIONAL Y SU IMPACTO POLÍTICO $^{1}$}

El recuento de resultados de 2012 es mixto; sin embargo, con marcada tendencia hacia la insatisfacción en la arena política, expresada sobre todo por medio de manifestaciones de desconfianza hacia el gobierno, que este año fue el de menor popularidad en América Latina. ${ }^{2} \mathrm{Si}$ bien es cierto ningún indicador social o económico se deterioró sustantivamente en este año, los escasos avances mostrados en los últimos años en la disminución de la pobreza y el aumento de la desigualdad, se aunaron al crecimiento del desempleo en este año, y convergieron con una seguidilla de escándalos de corrupción que permearon todos los poderes del Estado. En este contexto, el país mostró en 2012 el índice más bajo de apoyo a la democracia (gráfico), es decir, el respaldo al sistema no solo al gobierno.

Gráfico 1: Índice de apoyo promedio al sistema político

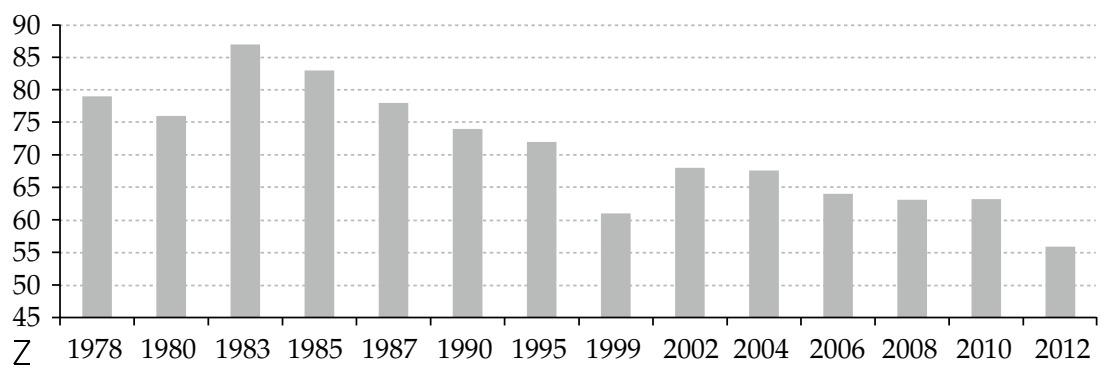

a/ Tomando como fuente la encuesta Barómetro de las Américas, el índice de apoyo promedio al sistema político se calcula sacando el promedio de las respuestas a las siguientes preguntas (se utiliza una escala de 1 a 7 ):

$\S$ ¿Hasta qué punto cree usted que los tribunales de justicia de su país garantizan un juicio justo? $\S$ ¿Hasta qué punto tiene usted respeto por las instituciones políticas de su país?

$\S$ ¿Hasta qué punto cree usted que los derechos básicos del ciudadano están bien protegidos por el sistema político de su país?

$\S$ ¿Hasta qué punto se siente usted orgulloso de vivir bajo el sistema político de su país?

$\S$ ¿Hasta qué punto piensa usted que se debe apoyar el sistema político de su país?

b/ Los estudios de 1978, 1980, 1983, 1985, 1990, 1995 y 2002 usaron una muestra del Área Metropolitana de San José. En los demás casos se utilizó una muestra nacional.

Fuente: Elaboración propia con datos de LAPOP.

Los datos estadísticos de esta sección fueron tomados de Compendio estadístico del Informe Estado de la Nación, con base en el Instituto Nacional de Estadística y Censo y Banco Central.

2 La presidenta Chinchilla obtuvo un 26\% de aprobación en un sondeo realizado en abril de 2012, el cual incluyó a 18 mandatarios latinoamericanos. 


\section{Coyuntura social}

Al analizar en detalle los indicadores sociales, los resultados pueden ser contradictorios, pues mientras ciertas áreas experimentan avances significativos, otras siguen acumulando rezagos y un mayor deterioro (Cuadro 1). El acceso a la educación ha mejorado en todos sus niveles mientras la esperanza de vida y las tasas de mortalidad materna e infantil obtienen resultados positivos en el tiempo. Sin embargo, a su vez, la tasa de desempleo (particularmente la femenina) se mantiene en niveles elevados, superiores al promedio de años anteriores a 2009 y los ingresos de los sectores informales y agrícolas se reducen.

La erosión fiscal que el país ha vivido durante los últimos cuatro años ha dado paso a una contracción real de la inversión social. Este escenario augura recortes para los siguientes años en áreas como salud, educación y protección social, en caso de que la recuperación económica siga siendo apenas moderada. Aunado a ello, el aparato institucional que administra el sector público social sigue siendo complejo, con políticas que no orientan el gasto según metas y resultados medibles.

Tampoco se registran mayores logros en materia de pobreza. La incidencia de la pobreza no mostró un descenso significativo respecto del nivel del año previo, aunque la cantidad de pobres en números absolutos sigue creciendo. El nivel registrado fue de 20,6\%, un punto porcentual menos que en 2011 (21,6\%). La desigualdad en el ingreso, por su parte, mantiene la tendencia creciente. El coeficiente de Gini aumentó de 0,515 (2011) a 0,518 (2012) y se mantiene la diferencia de ingresos de 18 veces entre el quintil más rico y el más pobre. Estos resultados negativos no son nuevos. Son parte de una tendencia negativa que el país ha venido mostrando durante los últimos 15 años.

\section{Coyuntura económica}

En materia económica el país mostró crecimiento moderado, no obstante el desempleo e indicadores socioeconómicos como la pobreza y la desigualdad no reflejan resultados positivos. Costa Rica comparte con otros países de la región latinoamericana la disyuntiva de cuál meta económica priorizar: crecer, controlar la inflación o generar empleo. Durante 2012 el PIB continuó creciendo al 5,1\% luego de la crisis de 2009. Este crecimiento fue mayor al registrado en 2011 (4,2\%), a pesar de un contexto internacional desacelerado y de recesión en la zona del euro. La inflación siguió mostrando resultados positivos, cerrando el año con un 4,6\%, manteniéndose baja y dentro de los rangos establecidos por el Banco Central de Costa Rica.

No obstante el crecimiento señalado, el desempleo se mantiene en niveles altos, con una tasa del 7,8. Superior en casi tres puntos a los niveles alcanzados previos a la crisis de 2009. La generación de empleo se redujo en comparación a 2011, los nuevos ocupados suman 22.725 en 2012, frente a 87.000 generados en 2011. Los mayores aportes a la generación de empleo en este año responden a las contrataciones de los servicios empresariales y telecomunicaciones. Por el contrario, en la industria, agro y comercio se registraron menos puestos de trabajo que el año anterior. 
Cuadro 1: Costa Rica: Principales indicadores económicos y sociales 2000-2012

\begin{tabular}{|c|c|c|c|c|c|c|c|}
\hline Indicador & 2000 & 2005 & 2008 & 2009 & 2010 & 2011 & 20121 \\
\hline $\begin{array}{l}\text { Ingreso nacional bruto (INB) } \\
\text { per cápita. Constante 2005, } \$ \\
\text { internacionales) }^{\text {a/ }}\end{array}$ & 7467 & 8650 & 10116 & 9917 & 10205 & 10497 & $\mathrm{~N} / \mathrm{D}$ \\
\hline Crecimiento del PIB (\%) & 1,8 & 5,9 & 2,7 & $-1,0$ & 4,7 & 4,2 & 5,1 \\
\hline $\begin{array}{l}\text { Crecimiento de las exportaciones } \$ \\
\text { corrientes) }\end{array}$ & $-12,2$ & 11,5 & 1,8 & $-7,6$ & 6,8 & 10,2 & 9,4 \\
\hline $\begin{array}{l}\text { Déficit/superávit Gobierno Central/ } \\
\text { PIB (\%) }\end{array}$ & $-3,0$ & $-2,1$ & 0,2 & $-3,4$ & $-5,3$ & $-4,1$ & $-4,4$ \\
\hline Inflación (IPC) (\%) & 10,2 & 14,1 & 13,9 & 4,0 & 5,8 & 4,7 & 4,6 \\
\hline Tasa de desempleo abierto (\%) & 5,2 & 6,6 & 4,9 & 8,4 & 7,3 & 7,7 & 7,8 \\
\hline $\begin{array}{l}\text { Cobertura de la PEA por seguro de } \\
\text { salud }(\%)\end{array}$ & 64,63 & 55,0 & 66,5 & 64,8 & 70,0 & 69,5 & $N / D$ \\
\hline $\begin{array}{l}\text { Cobertura promedio en educación } \\
\text { secundaria }(\%)\end{array}$ & 54,3 & 67,2 & 69,4 & 71,8 & 72,8 & 74,1 & 75,0 \\
\hline Esperanza de vida al nacer (años) & 77,7 & 79,1 & 79,1 & 79,2 & 79,0 & 79,3 & $N / D$ \\
\hline $\begin{array}{l}\text { Tasa de mortalidad infantil (por } 1.000 \\
\text { nacidos vivos) }\end{array}$ & 10,2 & 9,8 & 9,0 & 8,8 & 9,5 & 9,1 & $N / D$ \\
\hline $\begin{array}{l}\text { Tasa de víctimas de homicidios (por } \\
\text { cien mil habitantes) }\end{array}$ & 6,1 & 7,4 & 11,7 & 11,8 & 11,5 & 10,3 & $N / D$ \\
\hline Hogares pobres $(\%)^{b /}$ & 20,6 & 21,2 & 17,7 & 18,5 & 21,3 & 21,6 & 20,6 \\
\hline Coeficiente de Gini ${ }^{b /}$ & 0,487 & 0,485 & 0,498 & 0,516 & 0,508 & 0,515 & 0,518 \\
\hline $\begin{array}{l}\text { Relación entre el ingreso promedio } \\
\text { del hogar del V quintil y del I quintil } \\
\text { (veces) }^{c /}\end{array}$ & 9,7 & 9,4 & 9,0 & 10,1 & 10,9 & 11,8 & 12,1 \\
\hline
\end{tabular}

a/ Datos del Informe de Desarrollo Humano 2011, PNUD.

b/ Estas variables tienen como fuente las Encuestas de Hogares (INEC). Las cifras de 2000 a 2009 corresponden a las Encuestas de Hogares de Propósitos Múltiples (EHPM) y son totalmente comparables entre ellas. Las cifras de 2010 proceden de la Encuesta Nacional de Hogares (ENAHO), por lo cual no son comparables con las de años anteriores debido a: cambios en la muestra y en el cuestionario; utilización de las nuevas proyecciones de población de septiembre de 2008 para la determinación de los factores de expansión; aumento en el límite de la edad de la fuerza de trabajo, que pasó de 12 a 15 años; y cambios en la medición del ingreso y de la pobreza.

c/ Los quintiles son establecidos con base en el ingreso promedio per cápita del hogar.

Fuente: Elaboración propia con datos del Programa Estado de la Nación, el Banco Central de Costa Rica y el PNUD.

Las finanzas del Gobierno Central también experimentaron un leve deterioro, con un déficit de 4,4\% del PIB. La solvencia para hacerle frente al déficit es uno de los principales problemas económicos que encara el país. El gobierno invirtió sus dos primeros años en negociaciones con el Congreso para aprobar una reforma fiscal, que finalmente quedó 
sin efecto por errores de procedimiento según resolución de la Sala Constitucional. Por más de 15 años, el país sigue sin avanzar en la modernización de su política fiscal.

Finalmente, la balanza de pagos registró niveles similares en la cuenta corriente de los alcanzados en 2011: 5,4\% del PIB. Las importaciones se redujeron de manera importante. Destaca la caída en importaciones de bienes de capital, 10 puntos porcentuales menos en su tasa de variación. Los bienes de consumo y materias primas crecieron, aunque seis puntos porcentuales menos en relación con 2011. Las exportaciones también crecieron un punto porcentual menos que en 2011, a pesar de la desaceleración e incluso recesión experimentada por las principales economías del mundo (eurozona) y un tipo de cambio nominal que se mantuvo pegado a la banda inferior.

\section{Coyuntura política}

Los conflictos prevalecientes en la arena política durante todo el año pusieron al descubierto las cada vez mayores dificultades del sistema para llegar a acuerdos y negociaciones. En este panorama el gobierno perdió al inicio del año con la declaratoria de inconstitucionalidad de la reforma fiscal, su principal proyecto político. En materia de infraestructura destaca la paralización de su principal obra, la trocha fronteriza, por denuncias de corrupción. Otras de sus principales políticas, como la Red de Cuido y la Política de Seguridad y Paz, han tenido un desarrollo más bien lento, con pocos logros identificables y deben vencer la difícil situación fiscal del gobierno en los próximos años.

La conflictividad no solo se dio entre las fuerzas políticas, sino también dentro y entre poderes del Estado y desde la sociedad civil hacia el Ejecutivo por medio de un aumento en el número de acciones colectivas, tal como se reseñará más adelante.

El panorama político fue particularmente difícil para las estructuras partidarias, pues fueron múltiples las investigaciones emprendidas por el Tribunal Supremo de Elecciones, a raíz de las anomalías sobre el financiamiento de la campaña electoral de 2010. La revisión de los procedimientos seguidos por los partidos ha provocado la apertura de pesquisas -algunas incluso en sede judicial- para la mayoría de ellos, lo cual da muestra de los serios problemas organizativos que enfrentan estas agrupaciones. Este tema, como se verá adelante, además generó tensiones entre los diputados y el TSE.

Otro ámbito que sufrió un revés fue el de la rendición de cuentas y lucha contra la corrupción. La institucionalidad democrática se vio duramente afectada por la mala planificación y ejecución de una carretera en la zona fronteriza con Nicaragua, proyecto conocido como "la trocha fronteriza". Los medios de comunicación documentaron por varios meses los múltiples cuestionamientos, incluidos elementos relacionados con el diseño y construcción de la vía, así como el presunto pago de dádivas a algunos funcionarios públicos y contratos sobrevaluados. Esto provocó la apertura de procesos penales y administrativos, así como la salida de altos jerarcas de la cartera del Ministerio de Obras Públicas y Transportes (Mopt). También influyeron denuncias de corrupción en los cambios en las jerarquías del Ministerio de Hacienda, incluyendo al ministro quien lideraba el lobby por la reforma tributaria. 
Los procesos judiciales por delitos contra la función pública continúan siendo muy lentos y apenas un 3\% del total de esos casos ingresados al Ministerio Público terminan con una sentencia (Programa Estado de la Nación, 2012). En uno de los casos más importantes en los últimos años, en diciembre de 2012 y luego de ocho años de proceso judicial, un expresidente de la República fue declarado absuelto porque prescribieron las causas de las cuales se le acusaba por cohecho y corrupción. ${ }^{3}$ De hecho, uno de los indicadores políticos que más se ha deteriorado es la percepción ciudadana sobre si el gobierno está luchando contra la corrupción. También aumentó levemente el porcentaje de personas que dice haber participado en un acto de corrupción (victimización).

Gráfico 2: Porcentaje de personas que están de acuerdo con las afirmaciones descritas.

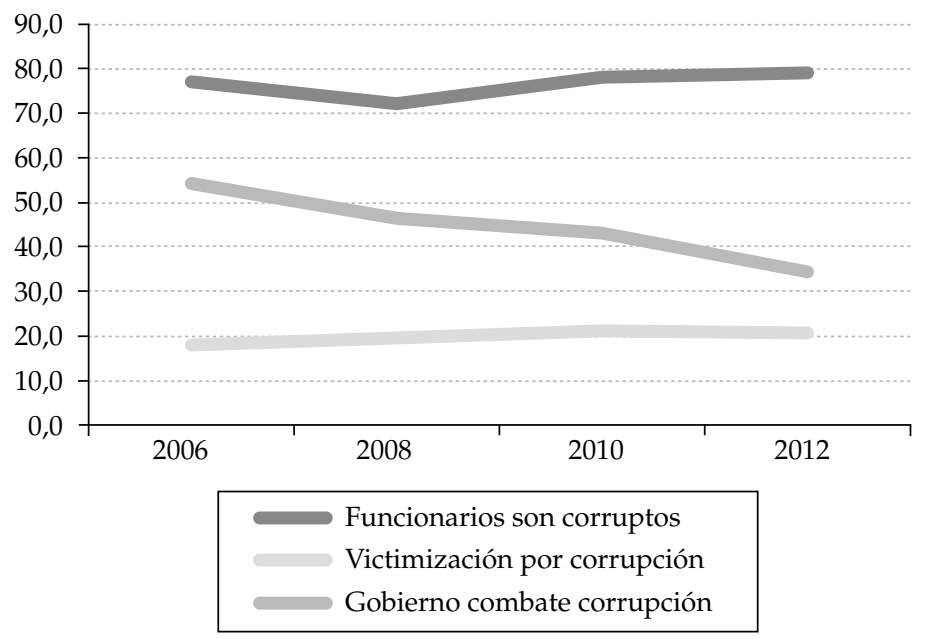

Fuente: LAPOP, Universidad de Vanderbilt.

Finalmente, en política exterior, en 2012 el conflicto limítrofe con Nicaragua tomó una nueva dinámica con la construcción de un camino paralelo a la frontera con esa nación, la llamada trocha. Este país acusó a Costa Rica de afectar el medioambiente con la construcción de dicha carretera y lo denunció ante la Corte Internacional de La Haya. En sus inicios la construcción de esta trocha generó, por primera vez en mucho tiempo, un apoyo casi unánime de la población. Sin embargo, en mayo de 2012 la presidenta Chinchilla comunica la existencia de irregularidades en la gestión de este proyecto, que provocaron la suspensión de las obras e impactaron negativamente la imagen del gobierno. Buena parte de la visibilidad del gabinete en 2012 ha estado relacionada con su actuación y defensa en este caso.

3 El Financiero. “Tribunal de Apelaciones absuelve a Miguel Angel Rodríguez". En http:/ /www.elfinancierocr. com/economia-y-politica/Tribunal-Miguel-Angel-Rodriguez-prescripcion_0_212978739.html 
En materia internacional destaca la condenatoria que sufrió el país ante la Corte Interamericana de Derechos Humanos, por la prohibición del procedimiento de fecundación in vitro. El fallo exige al país levantar la prohibición sobre este procedimiento.

También la negociación del Tratado de Libre Comercio con Colombia concentró importantes esfuerzos de la diplomacia comercial y ha aumentado el volumen de relaciones con ese país, en particular en materia de cooperación para el tema de seguridad. Este tema de igual manera ha sido el principal dinamizador de las relaciones de Costa Rica con el resto del istmo, al punto que algunos han acuñado la expresión de "segurización" de la integración centromericana.

\section{Movilización social}

Desde 2011 se notó un dramático aumento en la realización de acciones colectivas en el país. Según la base de datos de acciones colectivas del Programa Estado de la Nación, el total para 2011 es de 632 eventos, lo que significa un aumento del 85,8\% en la realización de acciones colectivas en comparación al año anterior. Desde 1995, año del que se registra este tipo de información, esta cifra de movilizaciones solo ha sido superada en tres ocasiones que constituían años "atípicos", y relacionados con eventos como la apertura del mercado de telecomunicaciones (Combo Ice), el monopolio de la revisión técnica vehicular (Riteve) y el Tratado de Libre Comercio Centroamérica-Estados Unidos. Sin embargo, en 2011 y parte de 2012 no existe ningún tema aglutinador de la protesta social, sino que las demandas son muy diversas, al igual que los actores que las promueven. Ello no solamente es indicador de que el gobierno está en problemas para atender esta abundante presión, sino también da cuenta de una sociedad civil fragmentada (Estado de la Nación, 2012).

Hacia finales de 2011 y hasta mayo de 2012, un tema que concentró las manifestaciones públicas fue la reforma fiscal, con alrededor de 70 acciones colectivas (Ramírez y Chacón, 2012).

El anuncio de un proyecto de ley de empleo público también ha generado agitación por parte de los sindicatos públicos, que ya se han manifestado en contra en varias ocasiones, y se prevé que continúen con su oposición en 2013. Los sectores de salud, educación y puertos fueron particularmente dinámicos en sus manifestaciones en 2012.

\section{CAMBIOS INSTITUCIONALES (Y CONSTITUCIONALES) Y CAMBIOS SUSTANCIALES EN POLÍTICAS PÚBLICAS}

La administración Chinchilla se dedicó a impulsar las políticas anunciadas en 2011, entre las cuales se destacan por su importancia la reforma fiscal, la política de seguridad y paz (Polsepaz), la política de red de cuido y recuperación de la infraestructura vial. Ya se mencionó su fracaso en el tema fiscal. El eje de seguridad sin duda ha sido el prioritario tanto en la retórica del Ejecutivo como también en el aumento de recursos destinados a las instituciones relacionadas. Se puede mencionar los proyectos de prevención de la violencia, el aumento de policías y las importantes donaciones de China para esta entidad. El gobierno ha anunciado leves reducciones en las estadísticas criminales en los últimos 
Gráfico 3: Acciones colectivas registradas por año, según administración (promedio anual)

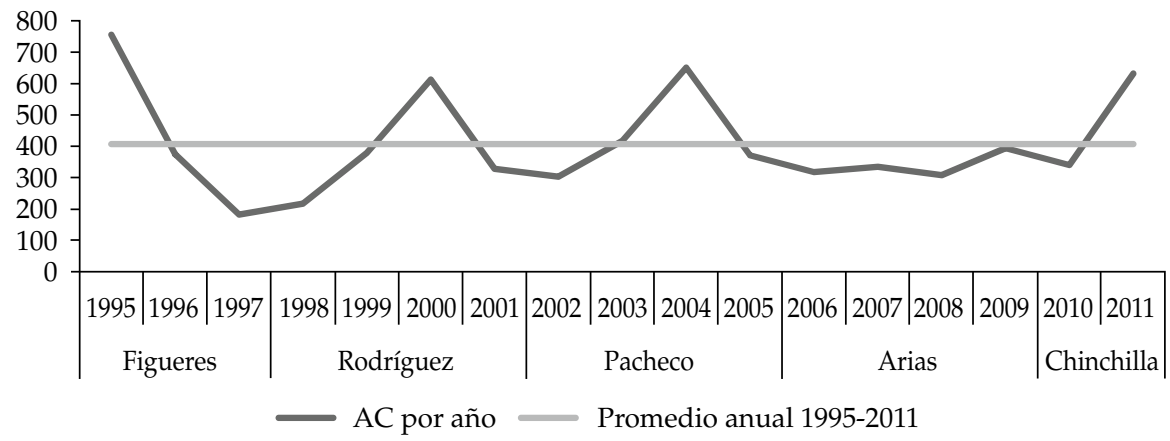

Nota: En 2007, la base de datos no registró el otro pico de acciones colectivas sobre el TLC, porque en el contexto del referéndum, la movilización se canalizó bajo el formato de una campaña electoral entre las dos posiciones - a favor y en contra- y no en forma de protesta ciudadana. No obstante este fue otro momento de alta movilización ciudadana.

Fuente: Elaboración propia basado en Ramírez-Chacón, 2012.

dos años. Por otra parte, la política de red de cuido y de infraestructura están menos desarrolladas, pues enfrentan limitaciones institucionales que complican su ejecución. En el caso de cuido implica coordinación con los gobiernos municipales y en el eje de infraestructura el reto es trabajar con la estructura del Ministerio de Obras Públicas y Transporte y los procedimientos de contratación pública, que por ahora no han logrado ejecutar la mayoría de los recursos de un importante préstamo del BID para este rubro.

Pese a la baja productividad de la Asamblea Legislativa que se expondrá más adelante, dos legislaciones aprobadas que destacaron en 2012 son la reforma a ley de tránsito y la ley antitabaco, ambas con alcances muy amplios para toda la población y que sobrevivieron exitosamente al complejo trámite legislativo.

En la estructura institucional se transformaron dos instituciones importantes, pero son cambios puntuales que no responden a ninguna estrategia comprensiva de reforma institucional:

- El Instituto de Desarrollo Agrario se convirtió por ley en el Instituto de Desarrollo Rural (IDER, ley del 22 de marzo de 2012 \# 9036), aunque sus nuevas funciones entraron a regir hasta seis meses después, el 29 de noviembre de 2012. Este cambio radica en un abordaje más amplio del desarrollo rural, que incluye pero no se limita a la cuestión agraria. La ley contiene un importante componente participativo en la toma de decisiones y en el control de resultados, y un mecanismo tributario que asegura ingresos nuevos y crecientes a la par de las nuevas competencias.

- La cartera de Telecomunicaciones fue reubicada desde el Ministerio de Ambiente, Energía y Telecomunicación (MINAET), hacia el Ministerio de Ciencia y Tecnología, ahora llamado de Ciencia, Tecnología y Telecomunicaciones (MICITT). Este cambio 
se realizó vía decreto ejecutivo firmado en junio de 2012, aunque se ejecutará en su totalidad hasta el 1 de febrero de 2013 (seis meses después de la publicación en el Diario Oficial La Gaceta). Por su lado, el Ministerio de Ambiente y Energía (MINAE) trabaja en la reorganización interna que le permita aprobar una ley para transformarse en el Rector del Sector de Ambiente, Energía, Aguas y Mares.

Adicionalmente, es relevante mencionar que se produjo un cambio de jerarca en la Contraloría General de la República, luego de que se venciera el plazo del nombramiento de la anterior. La Asamblea Legislativa designó en esa vacante a la contralora adjunta, por lo que no se prevé un cambio significativo en el perfil de esta robusta institución.

\section{RESULTADOS DE ELECCIONES NACIONALES Y SUBNACIONALES}

Si bien en 2012 no hubo procesos electorales, sí se produjo un movimiento tempranero muy dinámico de fuerzas políticas, en búsqueda de alianzas interpartidarias que les permita ampliar su margen de maniobra de cara a las elecciones de 2014. Dicho esto, ciertamente, la desafección partidaria es la actitud predominante con un 57,1\% que dice no simpatizar con ningún partido, el mayor porcentaje registrado desde 1993, según se muestra en el gráfico siguiente.

Gráfico 4: Evolución de la simpatía partidaria en Costa Rica, 1993-2012

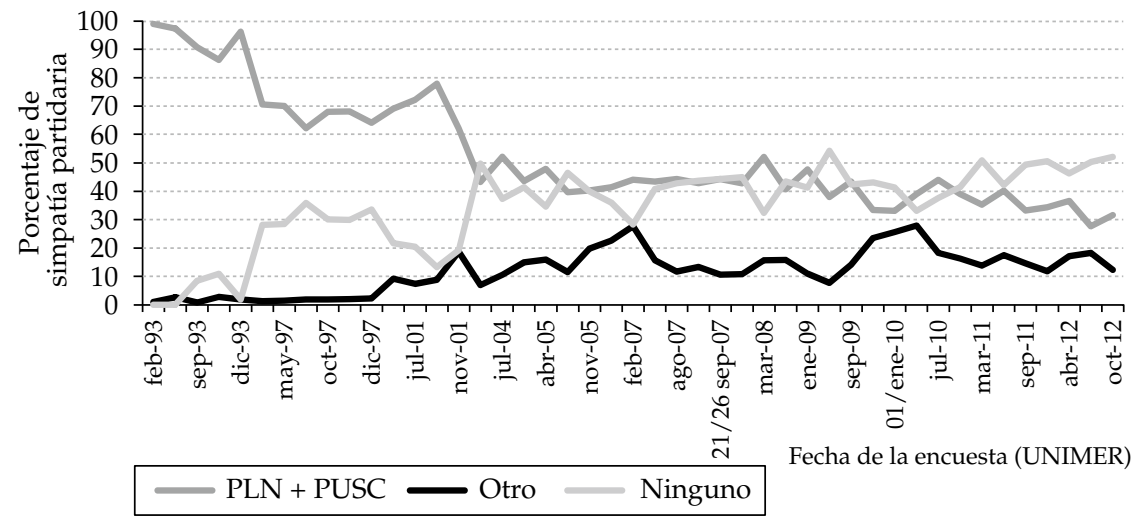

Fuente: Elaboración propia con base en las encuestas de opinión de UNIMER S.A.

Una alianza interpartidaria se empezó a gestar desde que un grupo de partidos de oposición ganó el directorio legislativo que históricamente había sido dominio del partido oficial (véase adelante). Ellos anunciaron que esta coalición podría extenderse a nivel electoral, aunque no se ha concretado en la práctica y tampoco lograron mantenerla para la siguiente elección del directorio. Paralelamente, dirigentes de diversos -y hasta antagonistas- partidos políticos han hecho públicos sus encuentros en búsqueda de un bloque de oposición al Partido Liberación Nacional. Otras alianzas políticas más bien han sido impulsadas por varias figuras nacionales que intentan organizar una alternativa desde la ciudadanía. 
A nivel interno en los partidos políticos se anunciaron las precandidaturas que estarían compitiendo en las elecciones primarias durante 2013. Cabe mencionar aquí el proceso del Partido Acción Ciudadana, que por el momento ha generado cuatro precandidaturas. El Partido Liberación Nacional inicialmente contaba también con cuatro precandidatos, que incluso produjeron inusuales y costosas campañas mediáticas personales, sin embargo, las negociaciones internas decantaron hacia una única precandidatura en la persona del actual alcalde de la capital San José.

En el nivel local, de acuerdo con el Código Municipal, 2012 fue de renovación de los puestos de presidente y vicepresidente de los Concejos Municipales. Como resultado de esta elección a lo interno de los concejos, el Partido Liberación Nacional (PLN) obtuvo la presidencia de los Concejos Municipales en 43 cantones (un 53\% del total), con lo cual conserva una mayoría de municipios, aunque mantiene su tendencia a la reducción, pues en 2010, al inicio de la administración Chinchillla, controlaba 78\%, y en 2011 un $60 \%$ de presidencias municipales.

\section{PODER EJECUTIVO}

En el Ejecutivo la principal característica refiere a la alta inestabilidad en el Gabinete, en ministerios clave para las principales políticas de este gobierno. Se consideraron las condiciones de 54 jerarcas -21 ministros y 33 viceministros-. Ciertamente, el $70 \%$ de las y los funcionarios considerados se desempeñaron en el pasado como jerarcas de ministerios y viceministerios, fueron diputados y diputadas, o bien ocuparon los cargos superiores en embajadas, presidencias ejecutivas y juntas directivas. No obstante, ello no evitó la alta inestabilidad.

Durante los primeros 24 meses de gestión (de mayo 2010 a mayo de 2012), 15 de los 21 ministros y ministras que iniciaron en mayo de 2010 dejaron sus carteras por diferentes motivos. De hecho este ha sido el gabinete con la mayor inestabilidad de las últimas cuatro administraciones. El otro Gabinete con más inestabilidad es el de la administración Rodríguez Echeverría (1998-2002), que perdió once de sus ministros en los primeros dos años. En el gobierno Pacheco de la Espriella (2002-2006), nueve jerarcas dejaron su cargo, y en el de Arias Sánchez (2006-2010) solo ocho (Programa Estado de la Nación, 2012). Para diciembre de 2012, la cantidad de cambios ascendió a 18 entre los ministros y 21 entre los viceministros (Cuadro 2).

Los cambios en el Gabinete son normales e incluso parte de las herramientas que tiene el Ejecutivo para hacer ajustes en la gestión política. No obstante, los datos para el país se tornan preocupantes debido a que varios de los cambios se dieron en áreas definidas como prioritarias por la Presidencia. Considerando los asuntos estratégicos incluidos en el Plan Nacional de Desarrollo, se observa que nueve ministerios ${ }^{4}$ fueron los encargados

4 Los nueve ministerios encargados de las áreas prioritarias del Gobierno son: Obras Públicas y Transportes, Salud, Educación Pública, Bienestar Social y Familia, Seguridad Pública, Comercio Exterior, Hacienda, Presidencia y Relaciones Exteriores y Culto. 
Cuadro 2: Cambios en el Gabinete durante la administración Chinchilla, mayo de 2010 a diciembre de 2012

\begin{tabular}{lcc}
\hline \multicolumn{1}{c}{ Ministerio } & $\begin{array}{c}\text { Cambio de } \\
\text { Ministro }^{\mathrm{a} /}\end{array}$ & $\begin{array}{c}\text { Cambio de } \\
\text { Viceministro }\end{array}$ \\
\hline Hacienda & 1 & $1^{\mathrm{b} /}$ \\
Obras Públicas y Transportes & 2 & $3^{\mathrm{c} /}$ \\
Relaciones Exteriores y Culto & 1 & $1^{\mathrm{d} /}$ \\
Salud & 1 & $2^{\mathrm{e} /}$ \\
Seguridad Pública & 1 & $4^{\mathrm{f} /}$ \\
Ambiente y Energía & 1 & $2^{\mathrm{g} /}$ \\
Planificación Nacional y Política Económica & 1 & $2^{\mathrm{h} /}$ \\
Justicia y Paz & 1 & $2^{\mathrm{i} /}$ \\
Ciencia y Tecnología & 1 & $1^{\mathrm{j} /}$ \\
Presidencia & 1 & $1^{\mathrm{k} /}$ \\
Trabajo y Seguridad Social & 1 & $1^{1 /}$ \\
Comunicación y Enlace & 1 & - \\
Vivienda y Asentamientos Humanos & 1 & - \\
Deporte & 3 & - \\
Turismo & 1 & $1^{\mathrm{m} /}$ \\
Cultura y Juventud & - & - \\
Educación Pública & - & - \\
Comercio Exterior & - & - \\
Bienestar Social y Familia & - & - \\
Agricultura y Ganadería & - & - \\
Economía, Industria y Comercio & - & - \\
Descentralización y Desarrollo Local & - & - \\
Total & 18 & - \\
\hline O/Se & & - \\
\hline
\end{tabular}

a/ Se contabiliza la cantidad de cambios del jerarca de la cartera

b/ El cambio se efectuó en el Viceministerio de Ingresos.

c/ Los cambios realizados se hicieron en el Viceministerio de Transporte Terrestre y Seguridad Vial, y dos veces en el de Infraestructura y Concesiones.

d/ El cambio se dio en el Viceministerio Administrativo

e/ Los cambios se dieron dos veces en los Viceministerios de Salud.

f/ Los cambios se dieron en los Viceministerios Administrativo, Gobernación y Policía, y dos veces en el de Seguridad Pública.

$\mathrm{g}$ / Los cambios se dieron en el Viceministerio del Sector Energía y en el Viceministerio del Sector Telecomunicaciones. Cabe recordar que este último fue trasladado al Ministerio de Ciencia y Tecnología.

h/ El cambio se dio dos veces en el Viceministerio de Planificación y Política Económica.

i/ El cambio se dio dos veces en el Viceministerio de Justicia.

j/ El cambio se dio en el Viceministerio de Ciencia y Tecnología.

k/ El cambio se dio en el Viceministerio de la Presidencia.

1/ El cambio se dio en el Viceministerio de Trabajo.

$\mathrm{m} /$ El cambio se dio en el Viceministerio de Juventud.

Fuente: Programa Estado de la Nación 2012, y actualización con base en prensa escrita. 
de coordinar las acciones en seis áreas de acción esenciales para el Ejecutivo: i) desarrollo de infraestructura, ii) políticas de bienestar social, en particular el programa "Avancemos" y la Red Nacional de Cuido, iii) seguridad ciudadana y iv) continuidad del proceso de apertura económica. A ello se suman otros dos temas, producto de acontecimientos ocurridos durante los primeros meses de la Administración: la reforma fiscal, que fue el proyecto más importante para el Gobierno durante 2011, y las relaciones exteriores ante el conflicto con Nicaragua.

En estas áreas estratégicas también se observa una alta rotación de los miembros del Gabinete. En seis de los nueve ministerios encargados de la coordinación en esos ámbitos hubo cambio de jerarca. Tal fue el caso de las carteras de Obras Públicas y Transportes, Salud, Seguridad Pública, Hacienda, Presidencia y Relaciones Exteriores y Culto. En esos mismos hubo además cambios en el Viceministerio, lo cual hizo más inestable la situación.

En suma, pese a estar conformado por personas con amplia experiencia política, el Gabinete de la actual Administración ha sufrido una alta inestabilidad, mayor que la de los últimos gobiernos. Los cambios de jerarcas pueden ser normales en cualquier gobierno, pero en este caso han sucedido en un contexto de denuncias de corrupción y mal manejo político que han terminado por deslegitimar la labor del Ejecutivo en su conjunto. El saldo es un desgaste en la imagen pública del Gobierno y de la Presidenta misma, sobre todo al considerar que el discurso anticorrupción fue parte medular de su campaña electoral. El liderazgo presidencial, que hasta 2011 era uno de los recursos políticos más importantes con que contaba la Mandataria para promover su agenda pública, también se ha visto afectado (Programa Estado de la Nación, 2012).

Así lo muestran los últimos datos divulgados en estudios de opinión pública. En la última encuesta de la empresa Unimer para el diario La Nación, de marzo de 2013, se observa que el 53\% de los costarricenses califican de mala o muy mala la labor de la Presidenta. Sólo un 13\% cree que su trabajo es bueno o muy bueno. Estos datos trascienden la personalidad de la Presidenta, afectando también a los partidos políticos, y la sensación de progreso del país en general. En efecto, solo 2,5\% de la ciudadanía piensa que el país camina por el rumbo correcto.

Estos datos reflejan un profundo descontento con el gobierno y la mandataria, pero además una fuerte disconformidad con la conducción del país en general. El resultado genera más apatía hacia la política y en particular hacia los partidos políticos. En perspectiva, el escenario durante 2013 -año electoral- no es fácil para los partidos, los cuales tendrán que activar sus maquinarias electorales en un contexto de niveles récord por los bajos márgenes de simpatías partidarias.

Como respuesta a las múltiples dificultades enfrentadas por la administración, en junio de 2012 la presidenta conformó una junta de notables a quienes les encargó recomendar reformas políticas para mejorar la gobernabilidad. Cabe mencionar que esta no es la primera vez que se elabora una propuesta de este tipo, anteriormente al menos en dos ocasiones se habían producido ejercicios, sin ninguna consecuencia 
en la práctica. ${ }^{5}$ Los notables esbozaron su informe de recomendaciones hacia el final del año, generaron un importante nivel de debate en los medios de comunicación. Las sugerencias apuntan hacia un regimen de tipo semiparlamentarista, en donde se introducirían la figura de la censura a ministros por parte de la Asamblea Legislativa y la convocatoria a elecciones legislativas anticipadas, entre otras. Sin embargo, estos cambios enfrentan un largo camino que trasciende el gobierno actual, pues la mayoría requiere reformas legales y constitucionales. ${ }^{6}$

\section{PODER LEGISLATIVO}

\section{Conformación del legislativo}

Vale recordar que la conformación de la Asamblea Legislativa para el periodo 20102014 favoreció la pluralidad por sobre la gobernabilidad, en tanto la distribución de curules se dio, privilegiando a partidos que con anterioridad no tenían mucha representación (Cuadro 3). Estos resultados revelan una mayor apertura del sistema político a fuerzas anteriormente invisibilizadas, pero a la vez agregan una mayor fragmentación. Situación que podría ayudar a explicar las fuertes dificultades para el trámite expedito de los asuntos parlamentarios durante los primeros dos años de gobierno.

Cuadro 3: Conformación del Congreso por período legislativo, según partido político

\begin{tabular}{lccc}
\hline \multirow{2}{*}{\multicolumn{1}{c}{ Partido político }} & \multicolumn{2}{c}{ Período legislativo } & Diferencia \\
\cline { 2 - 3 } & $2006-2010$ & $2010-2014$ & \\
\hline Liberación Nacional (PLN) & 25 & 24 & -1 \\
Unidad Social Cristiana (PUSC) & 5 & 6 & 1 \\
Acción Ciudadana (PAC) & 17 & 11 & -6 \\
Movimiento Libertario (ML) & 6 & 9 & 3 \\
Accesibilidad sin Exclusión (PASE) & 1 & 4 & 3 \\
Frente Amplio (FA) & 1 & 1 & 0 \\
Restauración Nacional (RN) & 1 & 1 & 0 \\
Unión Nacional (PUN) & 1 & & -1 \\
Renovación Costarricense (RC) & & 1 & 1 \\
Fragmentación partidaria & 3,3 & 3,9 & \\
\hline
\end{tabular}

Fuente: Decimosexto Informe Estado de la Nación, 2010.

5 En 2001, en su discurso oficial ante la Asamblea Legislativa el ex presidente Rodríguez había presentado un plan de cambio hacia un sistema semiparlamentario. En agosto de 2005, el ex-presidente Abel Pacheco recurrió también a la integración de una comisión de notables, aduciendo entonces motivos similares.

6 El informe completo de la Junta de Notables "Propuestas para fortalecer la funcionalidad y la calidad de la democracia costarricense", se puede descargar en: http:/ / es.scribd.com/doc/120853054/Informe-del-Grupo-de-Notables 
El número efectivo de partidos políticos (NEP) da cuenta de ello. Este indicador mide la fragmentación dentro del Congreso e indica la eventual facilidad o dificultad para lograr mayorías. Conforme el indicador se acerca a 1, revela una alta concentración de sillas legislativas en un solo partido, lo cual implica una mayor facilidad para tomar decisiones, pero en detrimento de la pluralidad. En 1986, por ejemplo, Costa Rica tenía un valor NEP de 2,21, que reflejaba una conformación bipartidista del Congreso. Para 2006 el NEP fue de 3,32 y para 2010 aumentó a 3,90, evidencia de una mayor fragmentación, y por consiguiente, de una mayor pluralidad. Vale anotar, además, que la Asamblea Legislativa que inició en 2010 es de las más fragmentadas de los últimos años, pues posee el segundo valor más alto de fragmentación partidaria desde 1986, solo superado por el de la Asamblea elegida en $2002(4,18)$.

\section{Desempeño legislativo durante 2011-2012}

En el Legislativo las divergencias entre partidos de oposición que conformaron la Alianza por Costa Rica -que se hizo del mando del Directorio Legislativo durante la legislatura 2011-2012- y cuestionamientos sobre su desempeño impidieron que este grupo de fuerzas continuara con el control del directorio legislativo. En ese escenario el oficialismo logró retomar el control legislativo -aunque siempre debilitado-, en negociación con partidos de oposición afines. El resultado muestra un Partido Liberación Nacional -oficialista- desgastado en la negociación legislativa, pues aunque logró una mejora de la representación en comisiones legislativas -en particular la de Asuntos Hacendarios que es clave en la discusión del Presupuesto de la República- tuvo que ceder la presidencia del directorio legislativo al Partido Accesibilidad sin Exclusión. Este es un partido que aumentó sustancialmente la cantidad de curules en las últimas elecciones, y que ha sabido negociar sus votos en el Congreso.

Esta debilidad del oficialismo también quedó patente en las discusiones legislativas sobre temas fiscales. Luego de que el Plan Fiscal fuera declarado inconstitucional por la Sala Constitucional, el Poder Ejecutivo envió al Congreso un conjunto de proyectos en materia fiscal y tributaria como Plan B. A pesar de la urgencia del tema fiscal, estos no han tenido un trámite ágil o expedito que le permita al gobierno hacer frente de manera más holgada a la difícil situación de déficit fiscal que se enfrenta el país.

Ya en año preelectoral, los partidos políticos acrecentaron las fuertes divisiones a lo interno que han mostrado durante los últimos tres años. En algunos casos las tensiones provocaron que fundadores y líderes históricos de algunas agrupaciones se separen de las estructuras partidarias, tal y como sucedió al menos en el Partido Accesibilidad sin Exclusión, el Partido Acción Ciudadana y en el Partido Unidad Social Cristiana.

Los principales datos del desempeño legislativo muestran una Asamblea Legislativa productiva en la cantidad de leyes aprobadas. No obstante, el análisis detallado evidencia que aunque existe buena cantidad de leyes que están directamente dirigidas a fortalecer el desarrollo humano sostenible, gran parte de ellas no contiene las fuentes de financiamiento necesarias para su cumplimiento. Además, el proceso de aprobación de leyes se vuelve cada vez más lento. 
En efecto, los primeros dos años de la administración Chinchilla fueron los más productivos en términos absolutos (206 leyes), si se comparan con las segundas legislaturas de los dos gobiernos anteriores (Pacheco y Arias). Durante el período 2011-2012 se aprobó un total de 93 leyes, 20 menos que en la legislatura anterior. Cabe señalar que la reducción en este año se dio sobre todo en las autorizaciones locales y los convenios y tratados internacionales. El mérito estuvo en mantener la cantidad de legislación sustantiva -legislación que, por sus alcances, tiene impacto sobre el desarrollo humano del paísprácticamente igual que el año anterior, pues pasó de 32 a 33 leyes (Cuadro 4).

No obstante, 68\% de la legislación sustantiva aprobada en la legislatura 2011-2012 concedió derechos a la población y amplió las competencias del Estado, pero no asignó recursos para su cumplimiento.

Esto es lo que el Programa Estado de la Nación ha denominado como "promesa democrática". Es la práctica de aprobar legislación que amplía las competencias del Estado, por la vía del reconocimiento de derechos ciudadanos o la asignación de nuevas obligaciones al aparato institucional, sin proveer los recursos necesarios para cumplir con esos mandatos. Esta costumbre genera presiones sobre la institucionalidad democrática, ya que, por falta de dinero, el resultado final son instituciones incapaces de cumplir con lo estipulado en la norma. Por ello sería conveniente establecer, como una obligación, que toda propuesta de ampliación del mandato estatal identifique claramente las fuentes de recursos que garantizarán la correcta aplicación de la nueva ley (Programa Estado de la Nación, 2012).

\section{RELACIÓN ENTRE LOS PODERES DEL ESTADO}

El sistema de pesos y contrapesos entre los distintos poderes del Estado se tensó en al menos dos circunstancias especiales. El acontecimiento más dramático se presentó

Cuadro 4: Leyes aprobadas en las primeras dos legislaturas de la administración Chinchilla Miranda, según tipo de leyes. 2010-2012

\begin{tabular}{lcc}
\hline \multirow{2}{*}{\multicolumn{1}{c}{ Tipo de legislación }} & 2010-2011 & 2011-2012 \\
\cline { 2 - 3 } & I Legislatura & II Legislatura \\
\hline Legislación sustantiva & 32 & 33 \\
Autorizaciones locales & 31 & 21 \\
Convenios y tratados internacionales & 39 & 21 \\
Legislación Circunstancial & 0 & 8 \\
Declaraciones y benemeritazgos & 8 & 5 \\
Exenciones, amnistías y condonaciones & 0 & 3 \\
Derogación & 0 & 1 \\
Presupuestos & 3 & 1 \\
Total por legislatura & 113 & 93 \\
\hline
\end{tabular}

Fuente: Elaboración propia con base en Programa Estado de la Nación, 2012. 
entre el Poder Judicial y la Asamblea Legislativa cuando esta última votó en contra de la reelección del magistrado Fernando Cruz. Tangencialmente también estuvo involucrado el poder Ejecutivo, pues se dio a conocer que tomó parte en el lobby para esa votación y además públicamente respaldó el derecho de los diputados de no reelegir. En sus declaraciones algunos diputados justificaron ese voto como un "llamado de atención" al Poder Judicial por resoluciones polémicas en materias eminentemente políticas. El Poder Judicial y amplios sectores sociales rechazaron esta actuación, por considerar que atentaba contra el principio básico de independencia judicial. Finalmente, un recurso de amparo presentado ante la Sala Constitucional invalidó la votación legislativa y reinstaló al magistrado Cruz en su puesto, no sin dejar dañadas las relaciones entre el legislativo y el judicial en un momento muy crítico de nombramiento de plazas vacantes de magistrados.

Este suceso presenta la punta del iceberg del fenómeno "judicialización de la política", que le ha generado roces al poder judicial con los demás poderes, pues se ve cada día más involucrado en la toma de decisiones de los más importantes temas-país, especialmente por medio de la Sala Constitucional. Por ejemplo, la Presidenta de la República acusó a la Sala de "no querer darle una reforma fiscal al país", cuando este órgano declaró que esa ley había sido aprobada con un procedimiento erróneo. En 2011 y 2012, nuevamente los diputados y la comisión de notables reactivaron el debate sobre la reforma a la ley de justicia constitucional. Aunque hay varios textos de proyectos de ley, en general se pretende reducir el ámbito de acción de la Sala y descongestionarla por medio de la descentralización de los recursos de hábeas corpus y amparos.

El segundo tema conflictivo remite a la clásica tensión entre el Ejecutivo y el Legislativo, al punto que la Presidenta de la República en su discurso anual de rendición de cuentas el 1 de mayo, solicitó a los diputados una "tregua" del enfrentamiento para aprobar leyes que el Ejecutivo considera prioritarias para el país. Esa solicitud de tregua no fue acogida por parte de los partidos de oposición que, como se dijo anteriormente, no han facilitado el trámite para los proyectos del Ejecutivo. A su vez, el control político de los diputados se mantuvo muy activo durante todo el año, en especial en las comisiones de control y gasto público, y las de investigación especial que tuvieron gran cantidad de material con los casos de la "trocha", el ministro de Hacienda, y las finanzas de los partidos políticos, entre otros.

\section{EVALUACIÓN GENERAL SOBRE EL FUNCIONAMIENTO Y CALIDAD DE LA DEMOCRACIA}

El 2012 fue un año donde las dificultades para el diálogo y la construcción de acuerdos se profundizaron. El conflicto es parte consustancial de la política, pero justamente en una democracia la política debe permitir la unidad y conciliación en ese contexto de antagonismos y diversidad (Mouffe, C. 1995). La incapacidad de procesar adecuadamente estos conflictos quedó en evidencia al observar los acontecimientos de enfrentamiento entre y dentro de los partidos políticos, sectores sociales, e incluso entre Poderes de la República. En términos agregados el año dio muestras del camino que le falta por recorrer 
al sistema político costarricense para renovarse como lo demandan los ciudadanos en la actualidad e incorporar esa amplia gama de conflictos como parte de las prácticas democráticas.

En este contexto, el segundo año de la administración de la Presidenta Chinchilla fue el inicio del fin de su mandato. Muy poco margen de acción le queda a este gobierno después del fracaso con su principal propuesta política como fue la reforma fiscal, sumado a los escándalos de la trocha y de la recomposición de su gabinete en varias de sus carteras más importantes. Además, con esa debilidad, el gobierno se vio enfrentado a un inusual número de movilizaciones ciudadanas.

Una democracia con los niveles más bajos de apoyo al sistema desde 1978 (solo 56\%), con serias críticas por la legitimidad de sus actores, denuncias cotidianas de corrupción y mala gestión, elevada movilización ciudadana y baja credibilidad sobre los mecanismos institucionales para que actores y Poderes de la República se interrelacionen. 2012 cerró con un nuevo intento de discusión sobre las principales reformas al sistema político, luego de que la Presidenta Chinchilla convocara a una comisión de notables. Un indicador que muestra la urgencia de cambios sustantivos en el plano político.

\section{REFERENCIAS}

Chinchilla, Laura. 2012. Discurso 1 de mayo de 2012 ante la Asamblea Legislativa.

El Financiero. "Tribunal de Apelaciones absuelve a Miguel Angel Rodríguez". 21 de diciembre 2012.

En http://www.elfinancierocr.com/economia-y-politica/Tribunal-Miguel-Angel-Rodriguezprescripcion_0_212978739.html

El País.cr. "Laura Chinchilla la peor presidente de América Latina". 21 de abril de 2012. http:/ /elpais. $\mathrm{cr} /$ frontend/noticia_detalle/1/65848

Mouffe's, Chantal. 1995. "The End of Politics and the Rise of the Radical Right". Dissent (Fall): 498-502.

Programa Estado de la Nación. 2010. Decimosexto Informe Estado de la Nación en Desarrollo Humano Sostenible. San José, Programa Estado de la Nación.

Programa Estado de la Nación. 2012. Decimoctavo Informe Estado de la Nación en Desarrollo Humano Sostenible. San José, Programa Estado de la Nación.

Ramírez, Pablo. 2012. Acciones colectivas en Costa Rica: balance 1995-2011. Ponencia preparada para el XVIII Informe Estado de la Nación. Programa Estado de la Nación-CONARE. San José.

University of Vanderbilt. 2006-2012. Latin American Public Opinion Project (LAPOP). 
Steffan Gómez es Máster en Estudios del Desarrollo por la Justüs Liebig Universität-Giessen de Alemania y Licenciado en Ciencias Políticas de la Universidad de Costa Rica. Profesor universitario y consultor. Se ha especializado en el área de política comparada en América Latina en temas de democracia, procesos electorales y sistemas de partidos políticos.

E-mail: sgomez@estadonacion.or.cr

Evelyn Villarreal es Máster en Estudios Políticos Latinoamericanos, Universidad de Oxford (Reino Unido), Licenciada en Ciencias Políticas y Relaciones Internacionales, Universidad de Costa Rica. Apoyó la coordinación de la Auditora Ciudadana sobre la Calidad de la Democracia (2001) y ha sido consultora técnica e investigadora del capítulo de Fortalecimiento de la Democracia del Informe Estado de la Nación durante varios años, especialmente en los temas sobre mecanismos de control y rendición de cuentas, transparencia, combate a la corrupción y participación ciudadana. Se desempeña también como profesora universitaria en temas de metodología y política centroamericana, en la Universidad de Costa Rica y en la Universidad Estatal a Distancia.

E-mail: evelynvillarreal@estadonacion.or.cr 